\title{
Adult Neurogenesis in Mammals: An Identity Crisis
}

\author{
Pasko Rakic \\ Department of Neurobiology, Yale University School of Medicine, New Haven, Connecticut 06520
}

The study of neurogenesis in the adult brain is among the most exciting and fastest moving areas of neuroscience today. In contrast to the high rate of neurogenesis in some vertebrates (Nottebohm, 2002), unambiguous evidence for new neurons in normal adult mammals ranging from rodents to primates has been confined to the dentate gyrus and olfactory bulb (Lois and AlvarezBuylla, 1964; Kaplan and Hinds, 1977; Kempermann et al., 1996; Kornack and Rakic, 1999, 2001a,b). These may serve as important model systems from which we can learn to introduce new neurons into more resistant brain structures (Rakic, 1998). However, the compelling desire for curing neurological disorders has fostered an uncommon willingness to accept unsound evidence for adult neurogenesis under normal and experimental conditions. Therefore, it is important to review the methods for identification of new neurons in the adult brain.

The realization that nerve cells in the adult are not renewed initially came from the observed paucity of mitotic divisions and a lack of transient forms from simple to more complex neuronal morphologies (Ramón y Cajal, 1928). The introduction of the ${ }^{3} \mathrm{H}$-thymidine $\left({ }^{3} \mathrm{H}\right.$-dT) autoradiographic method for detecting cell division revealed that, unlike most somatic cells that are continuously renewed or can be regenerated, neurons behave as a nonrenewable epithelium (Leblond, 1964). ${ }^{3} \mathrm{H}$-dT is incorporated into nuclear DNA during the $\mathrm{S}$ phase of the cell cycle, and the amount of incorporation in a given cell is directly proportional to the number of silver grains overlaying it; a high level of silver grains in autoradiograms, after a single intraventricular injection, can be used as a sign of the "birthday" of a neuron (Fig. 1a,b). In macaque monkey after intraventricular injection, ${ }^{3} \mathrm{H}-\mathrm{dT}$ is present in the bloodstream for $<10 \mathrm{~min}$, and thus provides a highly precise tool for dating the time of last cell division (Nowakowski and Rakic, 1974). Neurons are considered new only if the number of overlaying silver grains is at least $50 \%$ of that recorded in maximally labeled nuclei in the same specimen (Rakic 1973, 1977). Such a stringent criterion is needed to avoid misinterpreting light labeling caused by background or other artifacts as a sign of cell division (Nowakowski and Hines, 2000, 2002; Rakic, 2002). Indeed, the presence of both heavily and lightly labeled cells has been used as a criterion for confirming that the detected DNA synthesis is actually caused by cell proliferation (Angevine, 1965).

Over the past few decades ${ }^{3} \mathrm{H}$-dT autoradiography has been used as a method of choice for determination of the time of neuron origin in mammals. The most comprehensive data are available for rodents (rat) and primates (macaque monkey). All mayor classes of neurons in the structures that range from the

This work was supported in part by the National Institutes of Heath. I am grateful to P. Goldman-Rakic, K. Herrup, D. R. Kornack, E. A. Markakis, and N. Sestan for their insightful discussion and comments on this manuscript.

Correspondence should be addressed to Dr. Rakic at the above address. E-mail: pasko.rakic@yale.edu.

Copyright (C) 2002 Society for Neuroscience $\quad 0270-6474 / 02 / 220614-05 \$ 15.00 / 0$ spinal cord to the cerebral cortex have been examined, and their survey is beyond the scope of this mini-review. For the purpose of the present article, it is sufficient to state that with the exception of interneurons in the olfactory bulb and dentate gyrus, each CNS structure in both of these mammals was found to acquire its neurons during a specific developmental time window. Importantly, the duration of this time window is not related to the final quantity of neurons in a given structure [e.g., 1.2 million retinal ganglion cells in macaque monkey are generated during $40 \mathrm{~d}$ (E30-E70), whereas 1.5 million geniculate neurons are produced in <8 d (E36-E43) (Rakic, 1977; LaVail et al., 1991)]. Altogether, the results of these studies indicate that a species-specific size of a given structure is determined early in the proliferative zone by genes controlling cell production (i.e., onset, cessation, length of cell cycle, symmetric-asymmetric mode of cell division, and the rate of programmed cell death) as well as by regulation of the allocation of postmitotic cells by the gradients of attractive and repulsive molecules. These findings in mammals stand in contrast to the high rate of neurogenesis in many adult vertebrates (Nottebohm, 2002). Thus, overcoming the resistance of the brain to the acquisition of functionally competent new neurons will require an understanding of why neurogenesis ceases at the end of specific developmental time windows and why there are species-specific and regional variations in this phenomenon ( Rakic, 2002).

More recently, evidence for neurogenesis is being obtained by the use of the thymidine analog bromodeoxyuridine (BrdU), which also incorporates into DNA during S phase (Nowakowski et al., 1989). The advantage of this method is that its immunohistochemical detection is more easily combined with that of various cell class-specific markers to determine cell phenotype in small neurons such as granule cells that are difficult to distinguish from astrocytes. It was particularly useful for the detection of newly generated granule cells that were difficult to identify with the autoradiographic method. This approach also allowed for the analysis of changes in the production of specific cell types under various experimental conditions. However, the immunohistochemical approach can also lead to false conclusions if potential technical problems are ignored (Nowakowski and Hayes, 2000, 2002; Rakic 2002). At this time there are no established criteria for the use of BrdU as a marker of neuronal birth date. It is therefore crucially important to establish basic standards for detecting the genesis of new cells and their identity.

\section{Are all BrdU-labeled cells new?}

Labeling with BrdU is necessary, but not sufficient, to prove that a given cell has divided. Thus, BrdU is not a marker for cell division, but rather a marker for DNA synthesis. Furthermore, in contrast to ${ }^{3} \mathrm{H}$-dT autoradiography, BrdU immunohistochemistry is not stoichiometric (Nowakowski and Hines, 2000). Thus, the intensity or extent of labeling is highly dependent on the methods 

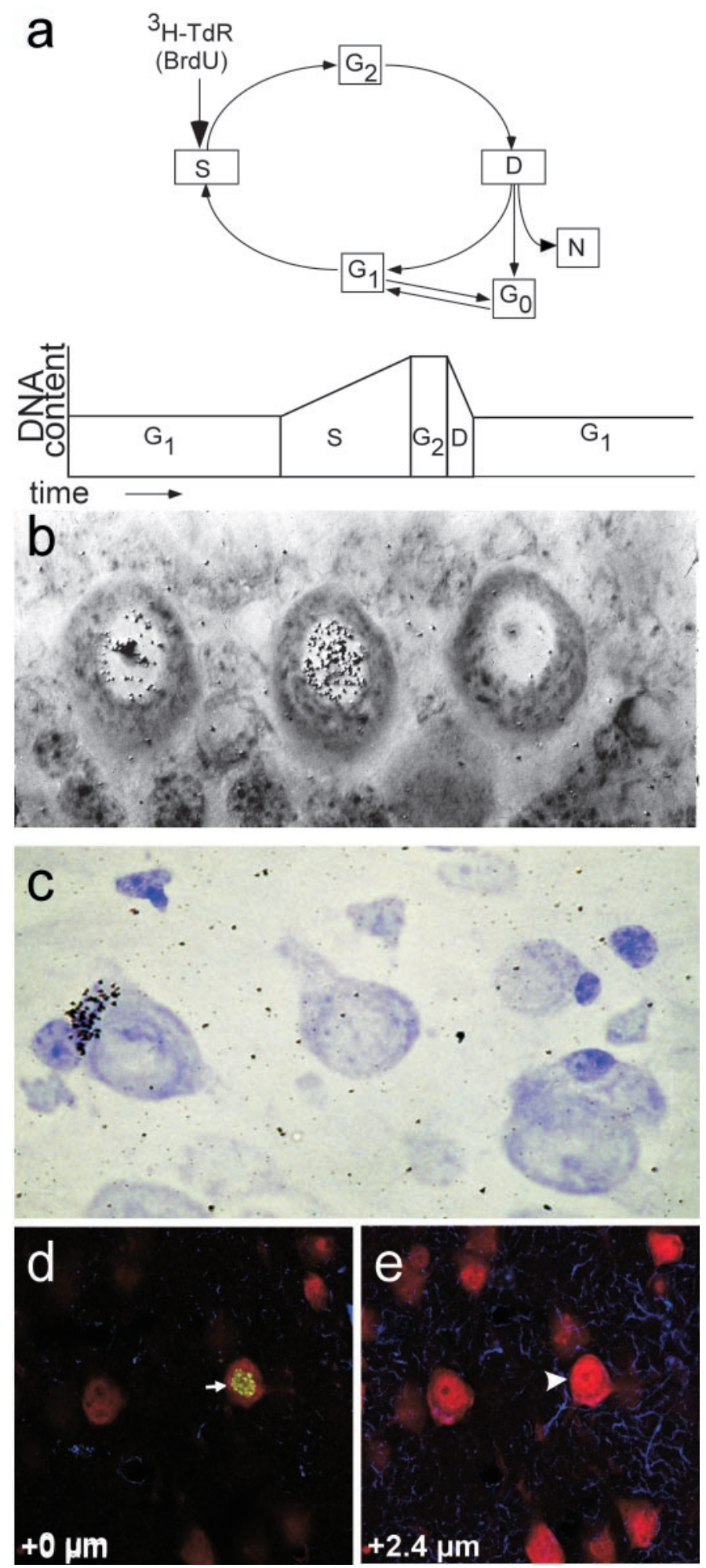

Figure 1. a, Graphic representation of the level of DNA during different phases of cell cycle $\left(G_{1}\right.$ and $G_{2}$, gap phases; $D$, mitotic division; $S$, synthesis phase). The synthesis of DNA can be detected by the incorporation of ${ }^{3} \mathrm{H}$-dT or its analog BrdU. The method of ${ }^{3} \mathrm{H}$-dT incorporation after a single injection of the isotope is stoichiometric, and thus allows distinction between doubling of DNA content during the S phase, signifying mitotic division, and the light label of $<50 \%$ of the maximum grain counts. $b$, The Purkinje cells in the middle and on the left can be considered as heavily labeled, whereas the five grains over the cell nucleus on the right may be caused by the variety of biological and technological factors, some of which are discussed in the text. Importantly, if the animal used for detection and does not necessarily reflect the magnitude of DNA replication. For this reason, BrdU labeling as a measure of cell division is especially vulnerable to misinterpretation. High and multiple doses of BrdU exacerbate this problem. Although $<50 \mathrm{mg} / \mathrm{kg}$ is commonly used to label dividing neurons in the developing brain, the multiple doses of $50-500 \mathrm{mg} / \mathrm{kg}$ often used in adult mammals can produce various artifacts. For example, a high dose may expose even low levels of normal DNA turnover or minor repairs as a heavy label in both ${ }^{3} \mathrm{H}$-dT and BrdU experiments (Fig. 1). However, BrdU is also considered to be a mutagen (Morris, 1991), and thus the higher doses may complicate the results in unpredictable ways. Significantly, many factors and external agents that modulate the proliferation of granule cells, such as seizures, are also known to cause cell damage leading to their death (Bengzon et al., 1997). Furthermore, damaged or degenerating neurons are known to activate cell cycle-associated proteins such as cyclins and ubiquitins and initiate abortive DNA synthesis leading to polyploidy that can persist for many months before the death of a cell (Neve et al., 2000; Katchanov et al., 2001; Copani et al., 2001; Yang et al., 2001). Finally, although not demonstrated directly in neurons, unscheduled DNA synthesis is an evolutionary device to provide additional gene copies to enhance transcription in metabolically more active cells or in situations of higher demand, as shown in hepatocytes (Anatskaya et al., 1994). This may occur in cells that have very little RNA to meet such demands. Indeed, granule cells may be particularly vulnerable to oxidative or other adverse conditions (e.g., NMDAreceptor-mediated cytotoxicity) and respond with a higher level of DNA repair (Pieper et al., 2000). Thus, the change of BrdU incorporation in response to various experimental conditions and exposure to drugs based solely on immunohistochemistry leaves open the possibility that the labeled nuclei belong to "old neurons" that have increased incorporation of exogenous nucleotides into their DNA (Fig. 2).

Because BrdU labeling is not a sufficient sign of cell division, neurogenesis must be demonstrated by independent means. Other markers used to detect "new" neurons in the adult brain, such as the nuclear antigen proliferating cell nuclear antigen, can also be expressed by nonproliferating neurons and are not valid substitutes (Ino and Chiba, 2000). An appropriate increase in the number of mitotic figures should be demonstrated after various experimental manipulations. Because the presence of mitotic figures itself cannot be used for the phenotypic fate determination of the cell, it is important to show that there is an appropriate increase in BrdU-labeled mitotic figures to establish that the

\section{$\leftarrow$}

were injected with 10 , instead of a single ${ }^{3} \mathrm{H}$-dT dose, this cell may be as heavily labeled as the one in the middle and could be falsely interpreted as divided. $c$, Interference (Nomarski) contrast microphotograph of a heavily labeled satellite glial cell in the frontal lobe of a monkey found $35 \mathrm{~d}$ after a single injection of ${ }^{3} \mathrm{H}-\mathrm{dT}(10 \mathrm{mCi} / \mathrm{kg}) . d$, Image of a cell in the adult macaque monkey prefrontal cortex that appears to be doublelabeled for BrdU and NeuN, but was proven to belong to two closely apposed single-labeled cells by the use of z-series analyses on a confocal microscope. An NeuN-positive neuron (red) appeared to be colabeled with BrdU ( green) at +0 level (arrow in $d$ ), but examination of a different focal plane $(+2.8 \mu \mathrm{m}$ level) reveals that the NeuN-positive nucleus and nucleolus actually belong to a neuron that is not BrdU-labeled (arrowhead in $e$ ). The BrdU-labeled nucleus apparently belongs to adult-generated satellite glia, which in the cerebral cortex typically associate with neuronal perikarya as seen also in $c$. Astrocytes in $d$ and $e$ are indicated by GFAP immunoreactivity (blue). For further information, see Kornack and Rakic (2001b) and Rakic (2002). 


\section{Incorporation of exogenous nucleotides Cell Proliferation \\ Cell Repair/Death}

Figure 2. Exogenous ${ }^{3} \mathrm{H}-\mathrm{dT}$ (red dots) or BrdU (blue squares) compete with the natural endogenous $\mathrm{H}-\mathrm{dT}$ for incorporation into nuclear DNA. $a$, During S phase of cell cycle, incorporation occurs predominately into new stands of DNA, and provided that the cell stops dividing, significant presence of these marks indicates the time of final cell division. $b$, Incorporation of nucleotides occurs at a slower rate as part of DNA turnover or repair (of both strands) or at the higher rate during an abortive cell cycle (predominately in a single strand) leading to recovery or death (for further explanation, see text and Fig. 1).

\author{
S-phase - single strand
}

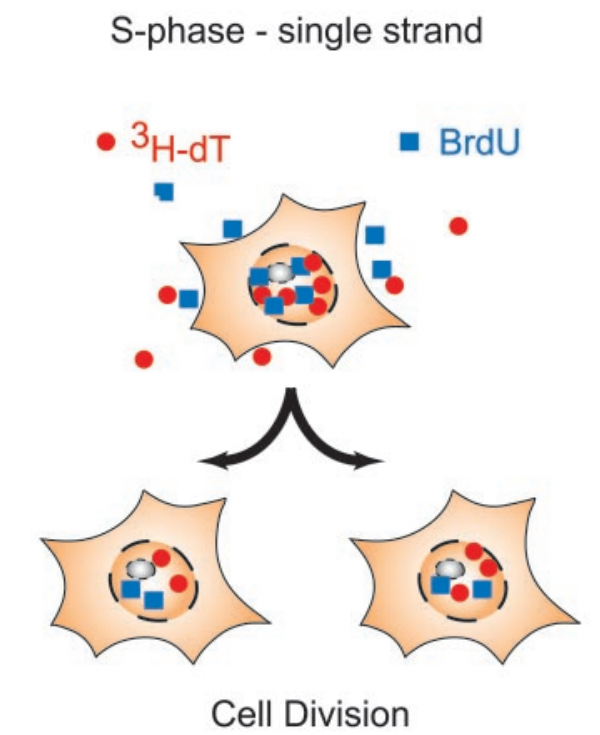

labeling is attributable to DNA replication associated with proliferation and not caused by unscheduled DNA synthesis. Tracing cell history from the phase of mitotic division through the bipolar migratory stage to the final differentiated states should be done by either ${ }^{3} \mathrm{H}$-dT or BrdU sequential experiments or by the retroviral gene transfer method. The use of $\mathrm{TuJ} 1$ expression in immature neurons is helpful. However, continuous generation of neurons should also be documented by an increase in the absolute number of neurons. If the numbers of neurons remain unchanged, an increase in the number of pyknotic cells, equivalent to the proposed neuronal addition, should be demonstrated (Nowakowski and Hayes, 2000).

\section{Are new cells neurons?}

As a next step, each newly generated cell must be unambiguously identified as a neuron. Double labeling is not necessary for identification of most CNS neurons, such as Purkinje cells or cortical neurons that are easily recognized (Fig. 1b,c), but is essential for identification of granule cells that are similar to glia in size, shape, and tinctorial properties in classical histological preparations. The use of BrdU immunodetection theoretically allows the use of other antibodies or methods for the determination of cell type, neurotransmitter phenotype, and even receptors on the surface of the labeled cell. Unfortunately, many of the so-called "neuron-specific" markers also label other cell classes as well. For example, the often used "neuron specific enolase", mitogen-activated protein-2, and TOAD 64 (TUC-4Ulip1), are inappropriate as specific markers for neurons, because they also react with astrocytes and/or oligodendrocytes (Deloulme et al., 1996; Sensenbrenner et al., 1997; Nacher et al., 2000; Ricard et al., 2001). The antigenic target of the NeuN antibody, used universally (including in our laboratory) as a neuron-specific marker has not as yet been identified. This antibody also has been reported to stain non-neuronal cells ranging from ependymoma (Parker et al., 2001) to bone marrow cells under certain conditions (Woodbury et al., 2000; Brazelton et al., 2001; Lu et al., 2001). On the other

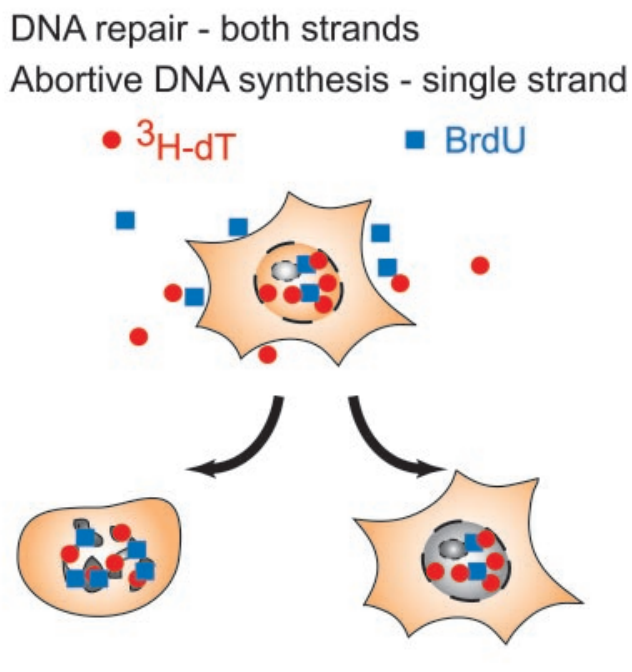

Apoptosis hand, NeuN does not recognize all neurons, and thus paradoxically, mitral or Purkinje cells (Fig. 1b), which do not immunoreact with NeuN, would not be considered as neurons! Is a single antigen to the unknown molecule sufficient to identify a "neuronal phenotype"? Demonstrating the connections of a cell (Stanfield and Trice, 1988; Markakis and Gage, 2000) or existence of synapses (Kaplan and Hinds, 1977) seems to be a reasonable requirement.

False-positive identification of neurons can also be obtained because of nonspecific binding of antibodies. Likewise, an antibody specific in rodents may not be equally specific in other species that may harbor molecules with similar epitopes in their non-neural cells. Thus, when the results are unusual or have extraordinary implications, it would seem wise to run essential controls and to establish antibody specificity. Finally, superimposition of small satellite glial cells closely apposed to the neuronal soma can mimic neuronal labeling, and Z-stacks of serial optical planes should be used to insure double labeling of a neuron (Fig. 2d,e) (Kuhn et al., 1997; Kornack and Rakic 2001b).

\section{What is an adult?}

Another parameter that should be more precisely defined in all studies is the term "adult." Notation of the precise age of experimental animals is particularly important in research on brain repair or on models of neurological and psychiatric diseases that afflict humans predominantly at middle or advanced age (Stewart et al., 2000). It has been shown, for example, that neurogenesis in the rodent dentate gyrus decreases with age, and that at 21 months, approximately the midpoint in their life span, is $<10 \%$ of that observed at 6 months (Kuhn et al., 1996). Furthermore, the rate of survival of newly born dentate granule cells in response to experimental conditions changes with age (Kempermann et al., 1988). It follows that results obtained in 4- to 6-week-old rats or monkeys $<3$ years old should not be generalized to the adult brain. Sometimes juvenile animals are classified as adults. The common use of weight as an index of an animal age is also not a 
sufficient criterion. The time of the initial mortality rate (IMR) and the time required for mortality to double (MRD) are more useful criteria as in studies of aging (Finch et al., 1990). The midpoint of the average life span, which is $\sim 1.5$ years of age in mice, 10 years in macaque, and $\sim 30$ years in human (Finch, 1990), may serve as a rough estimate of the tempo of aging among mammalian species. Because the aging process and duration of the life span vary greatly among mammalian species, among different strains of animals, as well as between genders, it seems obvious that a consensus should be developed and applied on what constitutes an adult organism in each species that serves as subjects in studies of adult neurogenesis.

\section{A need for uniform standards}

We have witnessed some remarkable discoveries and expect exciting advances in this field. However, even a cursory examination of the recent literature indicates that some studies do not satisfy even one basic criterion for neurogenesis, and very few met rigorous criteria. A more detailed discussion of the pitfalls of the methods used, as well as a criticism of the specific studies in primates is provided elsewhere (Korr and Schmitz, 1999; Nowakowski and Hayes, 2000; Kornack and Rakic, 2001b; Rakic, 2002). Those interested in the controversy about the claim for a large daily addition and/or turnover of neurons in the primate association neocortex should consult the recent detailed evaluation of the evidence (Rakic, 2002). It seems also prudent that some reports of the generation of "new neurons" after various experimental manipulations and exposure to drugs be re-evaluated using more stringent criteria. This is also true for the studies directing differentiation of stem cells along neuronal lineages or their transplantation to replenish normally nonrenewable neurons that have therapeutic promise (Anderson et al., 2001). Isolation of well characterized neuronal stem cells from the subependymal zone of a variety of adult species, including human, is a first step in this direction (Kakita and Goldman, 1996; Kirshenbaum et al., 1996; Doetsch et al., 1999; Laywell et al., 2000; Gage, 2001). However, standard and uniform criteria for the identification of "new cells" as well as "neuronal phenotype" should be applied by authors as well as by journal reviewers to assure scientifically sound advances in this promising field.

\section{REFERENCES}

Anatskaya OV, Vinogradov AE, Kudryavtsev BN (1994) Hepatocyte polyploidy and metabolism/life-history traits: hypotheses testing. J Theor Biol 168:191-199.

Anderson JD, Gage FH, Weissman IL (2001) Can stem cells cross lineage boundaries. Nat Med 7:393-395.

Angevine Jr JB (1965) Time of neuron origin in the hippocampal region. An autoradiographic study in the mouse. Exp Neurol [Suppl] 2:1-70.

Bengzon J, Kokaia Z, Elmer E, Nanobashvili A, Kokaia M, Lindvall O (1997) Apoptosis and proliferation of dentate gyrus neurons after single and intermittent limbic seizures. Proc Natl Acad Sci USA 94:10432-10437.

Brazelton TR, Rossi FM, Keshet GI, Blau HM (2000) From marrow to brain: expression of neuronal phenotypes in adult mice. Science 290:1775-1779.

Copani A, Uberti D, Sortino AM, Bruno V, Nicoletti F, Memo M (2001) Activation of cell cycle-associated proteins in neuronal death: a mandatory or dispensable path. Trends Neurosci 24:25-31.

Deloulme JC, Lucas M, Gaber C, Bouillon P, Keller A, Eclancher F, Sensenbrenner M (1996) Expression of the neuron-specific enolase gene by rat oligodendroglial cells during their differentiation. J Neurochem 66:936-945.

Doetsch F, Caille I, Lim DA, Garcia-Verdugo JM, Alvarez-Buylla A (1999) Subventricular zone astrocytes are neural stem cells in adult mammalian brain. Cell 97:703-716.

Finch CE (1990) Longevity, senescence and the genome. Chicago: University of Chicago.

Finch CE, Pike MC, Witten M (1990) Slow mortality-rate accelerations during aging in some animals approximate that of humans. Science 249: 902-905.

Gage FH (2000) Mammalian neural stem cells. Science 287:1433-1438.

Ino H, Chiba T (2000) Expression of proliferating cell nuclear antigen (PCNA) in the adult and developing mouse nervous system. Mol Brain Res 78:163-174.

Kakita A, Goldman JE (1999) Patterns and dynamics of SVZ cell migration in the postnatal forebrain: monitoring living progenitors in slice preparations. Neuron 23:461-472.

Kaplan MS, Hinds JW (1977) Neurogenesis in the adult rat: Electron microscopic analysis of light radiographs. Science 197:1092-1094.

Katchanov J, Harms C, Gertz K, Hauck L, Waeber C, Hirt L, Priller J, von Harsdorf R, Bruck W, Hortnagl H, Dirnagl U, Bhide GP, Endres M (2001) Mild cerebral ischemia induces loss of cyclin-dependent kinase inhibitors and activation of cell cycle machinery before delayed neuronal cell death. J Neurosci 21:5045-5053.

Kempermann G, Kuhn HG, Gage FH (1988) Experience-induced neurogenesis in the senescent dentate gyrus. J Neurosci 18:3206-3212.

Kempermann G, Kuhn HG, Gage FH (1996) Genetic influence on neurogenesis in the dentate gyrus of adult mice Proc Natl Acad Sci USA 9:19409-19414.

Kirschenbaum B, Nedergaard M, Preuss A, Barami K, Fraser RA, Goldman SA (1994) In-vitro neuronal production and differentiation by precursor cells derived from the adult human forebrain. Cereb Cortex 4:576-589.

Kornack DR, Rakic P (1999) Continuation of neurogenesis in the hippocampus of the adult macaque monkey. Proc Natl Acad Sci USA 96:5768-5773.

Kornack RD, Rakic P (2001a) Generation and migration of new olfactory neurons in adult primates. Proc Natl Acad Sci USA 98:4752-4757.

Kornack RD, Rakic P (2001b) Cell proliferation without neurogenesis in adult primate neocortex. Science 294:2127-2130.

Korr H, Schmitz C (1999) Facts and fictions regarding post-natal neurogenesis in the developing human cerebral cortex. J Theor Biol 200:291-297.

Kuhn HG, Dickinson-Anson H, Gage FH (1996) Neurogenesis in the dentate gyrus of the adult rat: age-related decrease of neuronal progenitor proliferation. J Neurosci 16:2027-2033.

Kuhn HG, Winkler J, Kempermann G, Thal LJ, Gage FH (1997) Epidermal growth factor and fibroblast growth factor-2 have different effects on neural progenitors in the adult rat brain. J Neurosci 17:5820-5829.

LaVail MM, Rapaport DH, Rakic P (1991) Cytogenesis in the monkey retina. J Comp Neurol 309:86-114.

Laywell ED, Rakic P, Kukekov VG, Holland EC, Steindler DA (2000) Identification of a multipotent astrocytic stem cell in the immature and adult mouse brain. Proc Natl Acad Sci USA 97:138883-13888.

Leblond CP (1964) Classification of cell populations on the basis of their proliferative behavior. Nat Cancer Inst Monog 14:119-150.

Lois C, Alvarez-Buylla A (1964) Long-distance neuronal migration in the adult mammalian brain. Science 264:1145-1148.

Lu D, Mahmood A, Wang L, Li Y, Lu M, Chopp M (2001) Adult bone marrow stromal cells administered intravenously to rats after traumatic brain injury migrate into brain and improve neurological outcome. NeuroReport 12:559-563.

Markakis EA, Gage FH (2000) Adult-generated neurons in the dentate gyrus send axonal projections to field CA(3) and are surrounded by synaptic vesicles. J Comp Neurol 406:449-460.

Morris SM (1991) The genetic toxicology of 5-bromodeoxyuridine immunohistochemical determination of the in mammalian cells. Mutant Res 258:161-188.

Nacher J, Rosell DR, McEwen BS (2000) Widespread expression of rat collapsin response-mediated protein 4 in the telencephalon and other areas of the adult rat central nervous system. J Comp Neurol 4:628-639.

Neve R, McPhie DL, Chen Y (2000) Alzheimer's disease; a dysfunction of the amyloid precursor protein. Brain Res 886:54-66.

Nottebohm F (2002) Why are some neurons replaced in adult brain? J Neurosci 22:624-628.

Nowakowski RS, Hayes NL (2000) New neurons: extraordinary evidence or extraordinary conclusion? Science 288:771a. See details in Technical Comment on line: http//www.sciencemag.org/cgi/content/ ful/288/5467/771a.

Nowakowski RS, Hayes NL (2002) Stem cells: the promises and pitfalls. Neuropsychopharmacology, in press.

Nowakowski RS, Rakic P (1974) Decrease of exogenous thymidine- $\mathrm{H}^{3}$ in the plasma of pregnant rhesus monkeys. Cell Tissue Kinet 7:189-194.

Nowakowski RS, Lewin SB, Miller MW (1989) Bromodeoxyuridine immunohistochemical determination of the lengths of the cell cycle and the DNA-synthetic phase for an anatomically defined population. J Neurocytol 18:311-318.

Parker JR, Armstrong DL, Strother D, Rudman DM, Dauser RC, Laurent JP, Deyd J, Rouah PE (2001) Antineuronal nuclei immunohistochemical staining patterns in childhood ependymomas. J Child Neurol 8:548-552. 
Pieper AA, Blackshaw S, Clements EE, Brat DJ, Krug DK, White AJ, Pinto-Garcia P, Favit A, Conover JR, Snyder SH, Verma A (2000) Poly(ADP-ribosyl)ation basally activated by DNA strand breaks reflects glutamate-nitric oxide neurotransmission. Proc Natl Acad Sci USA 97:1845-1850.

Rakic P (1973) Kinetics of proliferation and latency between final cell division and onset of differentiation of cerebellar stellate and basket neurons. J Comp Neurol 147:523-546.

Rakic P (1977) Genesis of the dorsal lateral geniculate nucleus in the rhesus monkey: site and time of origin, kinetics of proliferation, routes of migration and pattern of distribution of neurons. J Comp Neurol $176: 23-52$.

Rakic P (1998) Young neurons for old brains? Nat Neurosci 1:643-645.

Rakic P (2002) Neurogenesis in adult primate neocortex: an evaluation of the evidence. Nat Rev Neurosci 3:65-71.

Ramón y Cajal S (1928) Degeneration and regeneration of the nervous system (Day RM, translator, from the 1913 Spanish edition). London: Oxford UP.

Ricard D, Rogemond V, Charrier E, Aguera M, Bagnard D, Belin M-F, Thomasset N, Honnorat J (2001) Isolation and expression pattern of human Unc-33-like phosphoprotein 6/collapsin response mediator protein 5 (Ulip6/CRMP5): coexistence with Ulip2/CRMP2 in Sema3Asensitive oligodendrocytes J Neurosci 21:7203-7214.

Sensenbrenner M, Lucas M, Deloulme JC (1997) Expression of two neuronal markers, growth-associated protein 43 and neuron-specific enolase, in rat glial cells. J Mol Med 75:653-663.

Stanfield B, Trice JE (1988) Evidence that granule cells generated in the dentate gyrus of adult rat extend axonal projections. Exp Brain Res 72:399-406.

Steward O, Schauwecker PE, Guth L, Zhang Z, Fujiki M, Inman D, Wrathall J, Kempermann G, Gage FH, Saatman KE, Raghupathi R, McIntosh T (1999) Genetic approaches to neurotrauma research: opportunities and potential pitfalls of murine models. Exp Neurol 157:19-42.

Woodbury D, Schwarz EJ, Prockop DJ, Black IB (2000) Adult rat and human bone marrow stromal cells differentiate into neurons. J Neurosci Res 61:364-370.

Yang Y, Geldmacher DS, Herrup K (2001) DNA replication precedes neuronal cell death in Alzheimer's disease. J Neurosci 15:2661-2668. 